\title{
Use of Stress Wave to Evaluate The Repair Quality of Concrete Crack
}

\author{
Keng-Tsang Hsu ${ }^{1}$, Chia-Chi Cheng ${ }^{2}$, Chih-Hung Chiang ${ }^{2}$, and Hung-Hua Wang $^{3}$ \\ ${ }^{1}$ Assistant Professor, Department of Construction Engineering, Chaoyang University of Technology, \\ Taiwan \\ ${ }^{2}$ Professor, Department of Construction Engineering, Chaoyang University of Technology, Taiwan \\ ${ }^{3}$ Postgraduate, Department of Construction Engineering, Chaoyang University of Technology, \\ Taiwan
}

\begin{abstract}
The objective of this paper is to develop a nondestructive test technique based on stress wave propagation for evaluating the repair quality of concrete. Concrete structures frequently exist various types of cracks due to inferior environment and excessive loading. There are several crack repairing technique used in concrete construction. Epoxy-injection is the one used mostly in crack repairing. In this paper, a newly developed technique based on the stress wave was used to evaluate the repair quality of concrete crack. Numerical results show that the stress wave propagation of the impact-echo tests is capable of identifying the infill of epoxyinjection in the crack of repaired structures. The new technique under development has a high potential for evaluation of the quality of the repaired cracks.
\end{abstract}

\section{INTRODUCTION}

There is an increasing need for structural repairing to extend the service life of deteriorated concrete structures. The cracks of concrete structure are the important indicator for the structure health diagnosis. Because the development of strong epoxy adhesive, epoxy resin injection becomes the most popular method of structural repairing for reinforced concrete members in the repair industry. The repairing method which injects Epoxy resin into the crack of concrete members is relatively simple and cost-effective, increases the strength of existing concrete members, blocks moisture penetration of reinforced concrete members and reduces the chance of corrosion.

The most important factor in determination of the repairing quality is the injection condition of the crack. Epoxy adhesives are used as an injection material to repair cracks but air voids at the crack will reduce the repair strength. To ensure the repairing quality, the techniques able to detect air voids of the crack after concrete members been repaired are needed. In this paper, a newly developed technique based on the Time-of-Flight Diffraction Technique was used to evaluate the repair quality of concrete crack. The research will started from numerical simulation of the stress wave propagation.

\section{TIME-OF-FLIGHT DIFFRACTION TECHNIQUE}

To measure the depth of surface-opening cracks in concrete, two receivers are used and located on the opposite sides of the crack. Figs. 1(a) shows the instrument arrangement. The first receiver is located on the impact side and has a distance H0 to the impact point. The second receiver is located on the opposite side of the crack. Figs. 1(b) and (c) show typical waveforms recorded at the first and second receivers, respectively. After impact, the Rwave arrival at the first receiver will trigger the monitoring system. If the arrival time, $\mathrm{t}_{1}$, 
and the speed, $\mathrm{C}_{\mathrm{R}}$, of R-wave are known, the time of impact initiation can be calculated as $\left(t_{1}-H_{0} / C_{R}\right)$. The value of $t_{1}$ is negative because a pre-trigger mode is used in recording signals to avoid losing important information. The region behind the crack cannot be penetrated by waves generated by impact until diffraction at the crack tip occurs. Thus, the second receiver initially responds to the arrival of the diffracted $\mathrm{P}$-wave. The arrival time, $\mathrm{t}_{2}$, of the diffracted P-wave can be obtained by identifying the initial disturbance in the waveform recorded at the second receiver. Thus, the shortest travel time for P-wave from the impact point to the second receiver can be obtained as

$$
\Delta t=t_{2}-\left(t_{1}-H_{0} / C_{R}\right)=t_{2}-t_{1}+H_{0} / C_{R}
$$

Knowing the $\mathrm{P}$-wave speed, $\mathrm{C}_{\mathrm{P}}$, in concrete, the shortest travel length of $\mathrm{P}$-wave from the impact point to the second receiver can be calculated as $C_{P} \times \Delta t$. If the distances from the crack to the impact point and the second receiver are $\mathrm{H} 1$ and $\mathrm{H} 2$ respectively, the depth, $\mathrm{d}$, of the vertical surface-opening crack can be determined by the following equation:

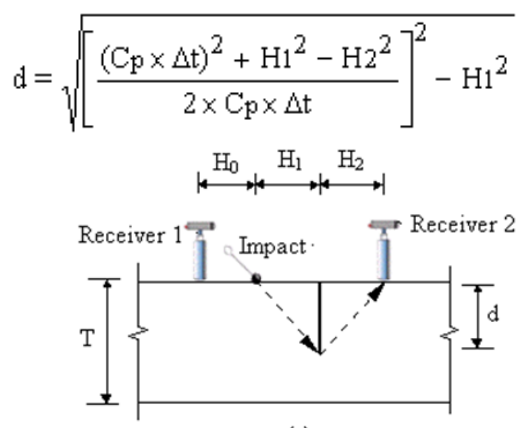

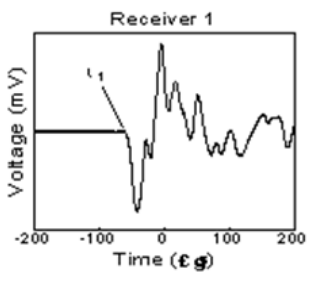

(b)

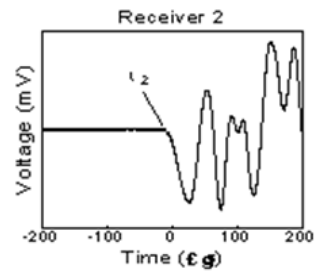

(c)

Fig. 1. Test scheme: (a) instrument arrangement; (b) waveform 1; (c) waveform 2.

\section{NUMERICAL SIMULATION}

In this paper, numerical simulations of the stress wave responses of crack were carried out using the explicit finite-element program LS-DYNA. All cases are simulated using 2-D axisymmetric, 4-node elements and isotropic models. Concrete is modeled as an isotropic material with a Poisson's ratio 0.2 and a density $2300 \mathrm{~kg} / \mathrm{m}^{3}$. A Young's modulus (E) of $33.1 \mathrm{GPa}$ is chosen to provide a P-wave speed of $4000 \mathrm{~m} / \mathrm{s}$, the material parameters of Epoxy resin and air used in numerical simulation are also shown in Table 1. The timehistory of nodal vertical displacements were recorded every $1.334 \mu \mathrm{s}$; and 1024 data were recorded in each simulation. 
Table 1. Material parameters of numerical simulation

\begin{tabular}{|c|c|c|c|c|}
\hline Material & $\begin{array}{c}\text { Wave speed } \\
\mathbf{C}_{\mathbf{P}, \mathbf{( m} / \mathbf{s})}\end{array}$ & $\begin{array}{c}\text { Density } \\
\left(\mathbf{k g} / \mathbf{m}^{\mathbf{3}}\right)\end{array}$ & $\begin{array}{c}\text { Elastic } \\
\text { modulus } \\
\mathbf{( p a )}\end{array}$ & $\begin{array}{c}\text { Acoustic } \\
\text { Impedance } \\
\mathbf{Z},\left(\mathbf{C}_{\mathbf{P}}{ }^{*} \boldsymbol{\rho}\right)\end{array}$ \\
\hline Air & 340 & 1.2 & - & 408 \\
\hline $\begin{array}{c}\text { Epoxy } \\
\text { Resin }\end{array}$ & 2400 & 1141 & $5.602 \mathrm{E} 9$ & 2738400 \\
\hline Concrete & 4000 & 2300 & $33.10 \mathrm{E} 9$ & 9200000 \\
\hline
\end{tabular}

\subsection{Numerical simulation of the time-of-flight diffraction with variable of different contact time}

The correctness of the numerical simulation is carried out in this section. In numerical simulation model, the depth of the crack is $10 \mathrm{~cm}$, the shape of force-time functions are half-sin which is used for introducing stress wave into numerical model as impactor. The distance of impact is setting at $4 \mathrm{~cm}\left(\mathrm{H}_{1}\right)$ beside the crack. The time-history of nodal vertical displacements were recorded at the distance of $4 \mathrm{~cm}\left(\mathrm{H}_{2}\right)$ located on the opposite side of the crack. Three force-time functions with different contact times as $10 \mu \mathrm{s}, 20 \mu \mathrm{s}$, and $30 \mu \mathrm{s}$ are chosen to perform the numerical model.

The results of time-history of nodal vertical displacements with different contact time as $10 \mu \mathrm{s}, 20 \mu \mathrm{s}$, and $30 \mu \mathrm{s}$ are shown in Fig.2. The nodal vertical displacements correspond to the arrival of the diffracted P-wave and the arrival time $\left(\mathrm{t}_{2}\right)$ of the diffracted P-wave is the same, $55 \mu \mathrm{s}$, for different contact time $(10 \mu \mathrm{s}, 20 \mu \mathrm{s}$, and $30 \mu \mathrm{s})$. According the results of numerical simulation, the depth of the crack can be calculated by using Eq.(2) as $9.95 \mathrm{~cm}$. Comparing with $10 \mathrm{~cm}$, the error percentage of numerical simulation results is below $1 \%$, so the numerical simulation was proved to be valid.

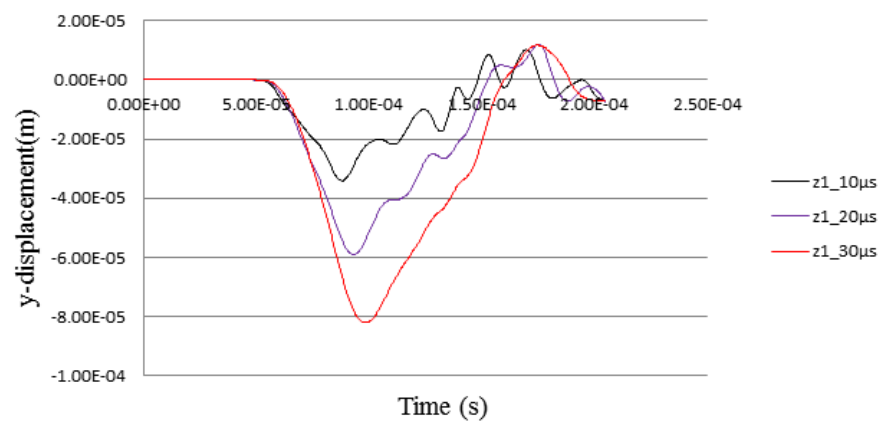

Fig. 2. waveform of time-of-flight diffraction with different contact-time

\subsection{Numerical simulation of different injection condition of crack repairing}

This section examines the stress wave propagation after the epoxy resin material filled in the crack with different partly filled scenarios. In numerical simulation, the depth of crack is also setting to $10 \mathrm{~cm}$ and the contact time of force-time function is $20 \mu \mathrm{s}$ in all cases. The variables of different epoxy resin injection scenarios in numerical simulations are shown in Table 2 and Fig. 3. For all the models, the epoxy is filled from the top surface and the air pack of the crack is underneath the epoxy. 
Table 2. Variables of different epoxy resin injection scenarios

\begin{tabular}{|c|c|c|c|}
\hline Code & $\begin{array}{c}\text { Length of Epoxy Resin } \\
(\mathbf{c m})\end{array}$ & $\begin{array}{c}\text { Length of Air } \\
(\mathbf{c m})\end{array}$ & Remark \\
\hline $\mathrm{E} 0 \mathrm{~cm} \_\mathrm{A} 10 \mathrm{~cm}$ & 0 & 10 & Non- epoxy injection \\
\hline $\mathrm{E} 2 \mathrm{~cm} \_\mathrm{A} 8 \mathrm{~cm}$ & 2 & 8 & Partial epoxy injection \\
\hline $\mathrm{E} 4 \mathrm{~cm} \_\mathrm{A} 6 \mathrm{~cm}$ & 4 & 6 & Partial epoxy injection \\
\hline $\mathrm{E} 6 \mathrm{~cm} \_\mathrm{A} 4 \mathrm{~cm}$ & 6 & 4 & Partial epoxy injection \\
\hline $\mathrm{E} 8 \mathrm{~cm} \_\mathrm{A} 2 \mathrm{~cm}$ & 8 & 2 & Partial epoxy injection \\
\hline $\mathrm{E} 10 \mathrm{~cm} \_\mathrm{A} 0 \mathrm{~cm}$ & 10 & 0 & Fully epoxy injection \\
\hline $\mathrm{E} 0 \mathrm{~cm} \_\mathrm{C} 10 \mathrm{~cm}$ & 0 & - & Non-crack case \\
\hline
\end{tabular}

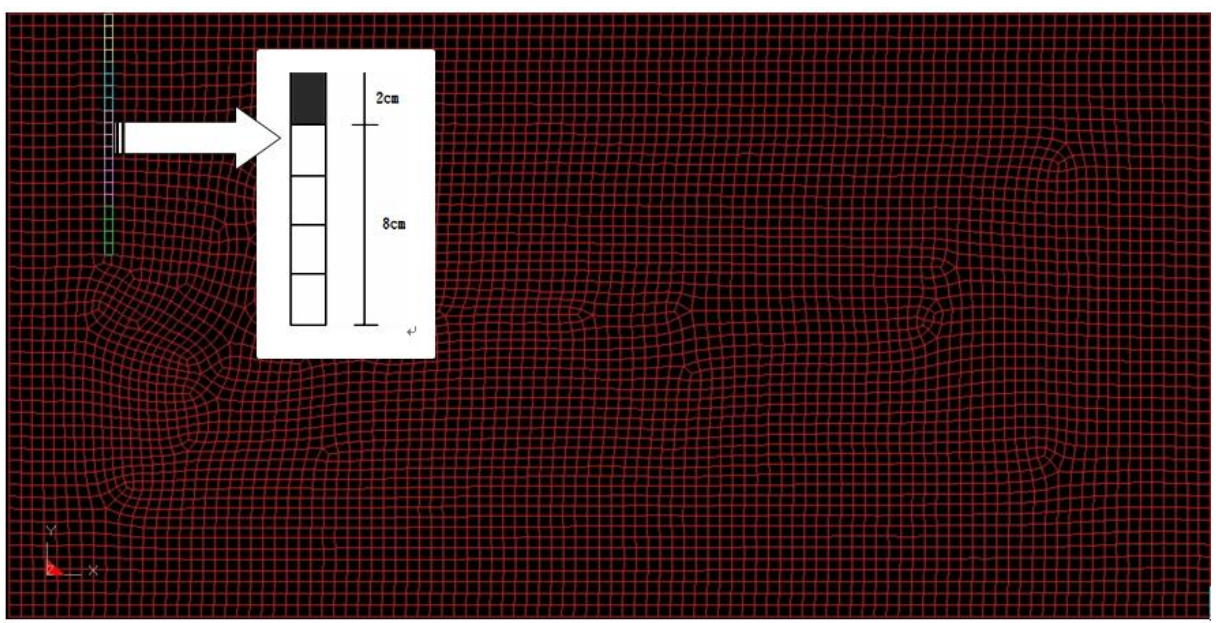

Fig. 3. Numerical model of stress wave with different epoxy injection condition (Labled E2 cm_A8 $\mathrm{cm})$

The results of time-history of nodal vertical displacements with different condition of epoxy resin injection are shown in Fig.4. The amplitude of $R_{\max }$ in time-history of nodal vertical displacement waveform is used as the parameter for investigation as shown in Fig. 5. The time-histories of nodal vertical displacements are varied with different scenarios of epoxy resin injection. Table 3 summarizes the maximum displacement of waveform $\left(R_{\max }\right)$ for all the cases. The maximum value of nodal vertical displacements $\left(\mathrm{R}_{\max }\right)$ is obtained from the non-crack case. The $\mathrm{R}_{\max }$ of non-crack case $(\mathrm{E} 0 \mathrm{~cm}-\mathrm{C} 10 \mathrm{~cm})$ from the Table $3 \mathrm{can}$ be compared with the fully epoxy injected case $\left(E 10 \mathrm{~cm} \_A 0 \mathrm{~cm}\right)$, the value of $R_{\max }$ attenuation was $11.4 \%$. In addition, the maximum displacement of the R-wave decreases with the decrease of length of epoxy resin injection.. Loss percentage of $R_{\max }$ with different epoxy resin injection condition was shown in Fig. 6.

Table 3. Maximum displacement of waveform with different epoxy resin injection condition

\begin{tabular}{|l|c|c|c|}
\hline \multicolumn{1}{|c|}{ Code } & $\begin{array}{c}\text { Maximum displacement } \\
\text { of waveform } \\
\left(\mathbf{R}_{\mathbf{m a x}}\right), \mathbf{m}\end{array}$ & $\begin{array}{c}\text { Loss percentage of } \mathbf{R}_{\mathbf{m a x}} \mathbf{( \% )} \\
\left.\text { (Base on } \mathbf{E 0} \mathbf{c m} \_\mathbf{C 1 0} \mathbf{~ c m}\right)\end{array}$ & Remark \\
\hline $\mathrm{E} 0 \mathrm{~cm} \_\mathrm{A} 10 \mathrm{~cm}$ & $-5.90 \mathrm{E}-05$ & 72.0 & Non- epoxy injection case \\
\hline $\mathrm{E} 2 \mathrm{~cm} \_\mathrm{A} 8 \mathrm{~cm}$ & $-1.09 \mathrm{E}-04$ & 48.3 & Partial epoxy injection case \\
\hline $\mathrm{E} 4 \mathrm{~cm} \_\mathrm{A} 6 \mathrm{~cm}$ & $-1.46 \mathrm{E}-04$ & 30.8 & Partial epoxy injection case \\
\hline $\mathrm{E} 6 \mathrm{~cm} \_\mathrm{A} 4 \mathrm{~cm}$ & $-1.76 \mathrm{E}-04$ & 16.6 & Partial epoxy injection case \\
\hline $\mathrm{E} 8 \mathrm{~cm} \_\mathrm{A} 2 \mathrm{~cm}$ & $-1.86 \mathrm{E}-04$ & 11.8 & Partial epoxy injection case \\
\hline $\mathrm{E} 10 \mathrm{~cm} \_\mathrm{A} 0 \mathrm{~cm}$ & $-1.87 \mathrm{E}-04$ & 11.4 & Fully epoxy injection case \\
\hline $\mathrm{E} 0 \mathrm{~cm} \_\mathrm{C} 10 \mathrm{~cm}$ & $-2.11 \mathrm{E}-04$ & 0.0 & Non-crack case \\
\hline
\end{tabular}




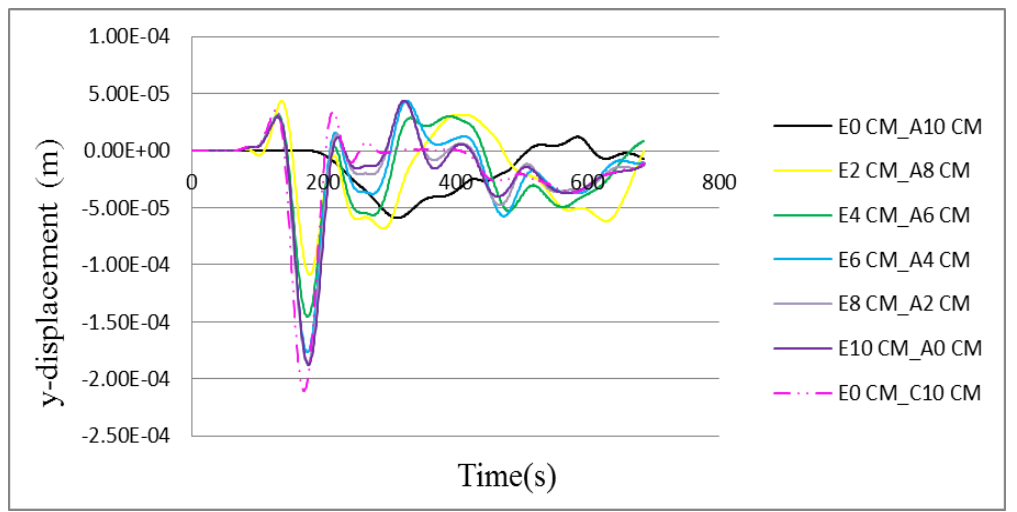

Fig. 4. Time-history of nodal vertical displacements with different epoxy resin injection condition

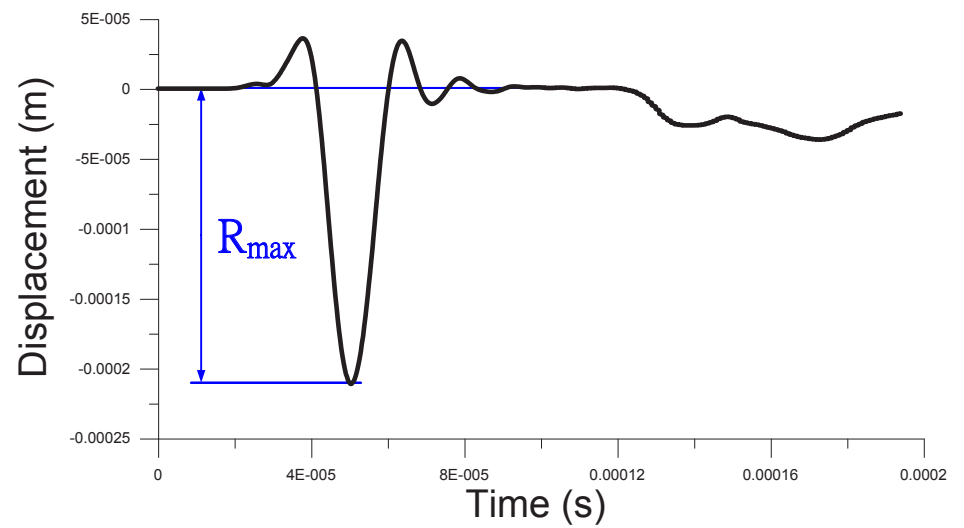

Fig. 5. The length of $R_{\max }$ in time-history of nodal vertical displacement waveform

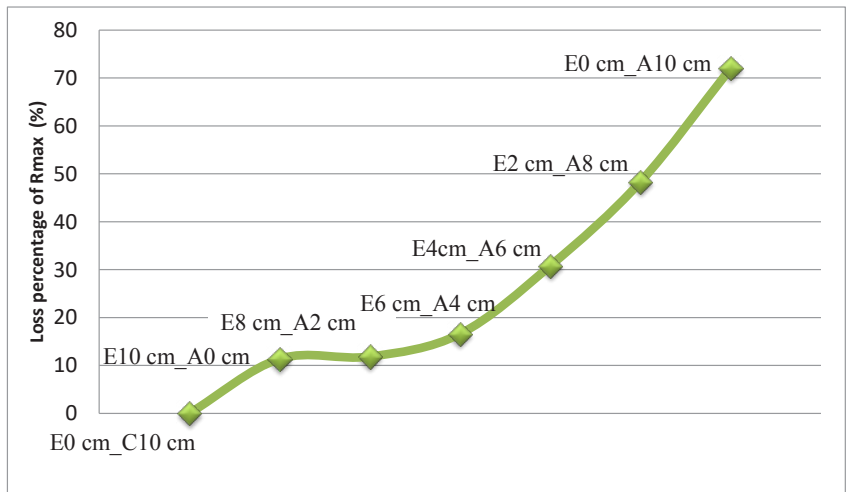

Fig. 6. Loss percentage of $R_{\max }$ with different epoxy resin injection condition 


\section{CONCLUSIONS}

Numerical simulation results show that for surface opening crack partially filled by epoxy resin, the maximum displacement of the R-wave can be served as a parameter to evaluate the different injection condition of crack. The maximum displacement of the R-wave decreases with the decrease of the length of epoxy resin in the crack. The technique has a great potential for evaluation of the repair quality of concrete structural cracks injected by epoxy resin.

\section{References}

1. Nikolaos Zoidis, Efthymios Tatsis, Christos Vlachopoulos, Anastasios Gotzamanis, Jesper Stærke Clausen, Dimitrios G. Aggelis, Theodore E. Matikas, "Inspection, evaluation and repair monitoring of cracked concrete floor using NDT methods", Construction and Building Materials, Volume 48, November 2013, Pages 1302-1308.

2. Hongqiang Chu, Linhua Jiang, Chuansheng Xiong, Lushen You, Ning $\mathrm{Xu}$, "Use of electrochemical method for repair of concrete cracks", Construction and Building Materials, Volume 73, 30 December 2014, Pages 58-66.

3. D.G. Aggelis, T. Shiotani, "Repair evaluation of concrete cracks using surface and through-transmission wave measurements", Cement and Concrete Composites Volume: 29, Issue: 9, October, 2007, pp. 700-711.

4. Aggelis, D.G., Hadjiyiangou, S., Chai, H.K., Momoki, S., Shiotani, T., "Longitudinal waves for evaluation of large concrete blocks after repair ", NDT and E International Volume: 44, Issue: 1, January, 2011, pp. 61-66.

5. D.G. Aggelis, T. Shiotani, D. Polyzos, "Characterization of surface crack depth and repair evaluation using Rayleigh waves", Cement and Concrete Composites, Volume 31, Issue 1, January 2009, Pages 77-83.

6. Lin, Y., Hsu, K.T., and Cheng, C.C., "Evaluating Bond Quality at Steel/Concrete Interfaces Using the Normalized Impact-Echo Spectrum," Modern Physics Letters B, vol.11, no.22, pp.1001-1006,(2008)

7. C. C Cheng, K.C. Pei, and J.H. Wu, "Development of imaging techniques for evaluating the rc plate containing epoxy-repaired delamination," Key Engineering Materials, vols 321-323,pp.348-351., Aug, (2006).

8. K. T. Hsu, C. C. Cheng, and Y.C. Lin, "Use Impact-echo Method to Evaluate Bond of Reinforced Concrete Subjected to Early-Age Vibration," Journal of Solid Mechanics and Materials Engineering, Vol. 2, No. 12, Dec, (2008). 